\title{
It Gets Better: A Content Analysis of Health Behavior Theory in Anti-Bullying YouTube Videos
}

\author{
Cameron Lister*, Elizabeth Brutsch, Amanda Johnson, Caitlin Boyer, P. Cougar Hall, Joshua West \\ Department of Health Science, Brigham Young University, Provo, UT \\ *Corresponding authorE-mail: camearlister@gmail.com
}

\begin{abstract}
Bullying is a pervasive problem that affects children and adolescents of all backgrounds. Public Service Announcements (PSAs) spread through social media present a unique opportunity to reach many young people and teach skills for dealing with bullying. The purpose of this paper is to examine health behavior theory content of antibullying YouTube PSAs, and other YouTube videos containing anti-bullying messages. This study design comprised a content analysis for health behavior theory of anti-bullying YouTube videos. Videos were selected from www.YouTube.com using specific search terms typed into the search tool bar. Three graduate students trained in health behavior theory coded the videos. Results demonstrate that most anti-bullying YouTube videos do not incorporate health behavior theoretical constructs. Videos containing links to other websites were found to have greater inclusion of health behavior theory constructs. Theory was also positively associated with the number of views $(\mathrm{p}<.05)$. This paper represents the first in-depth content analysis for health behavior theoretical constructs in YouTube videos targeting bullying PSAs. Organizations should incorporate health behavior theories when developing PSAs to maximize behavioral impact, and to achieve high viewership. Overall anti-bullying videos on YouTube are ineffective in both utilizing theory and garnering views.
\end{abstract}

Keywords: bullying, health behavior, PSA, social media, YouTube

\section{Introduction}

Adolescent bullying is a serious public health concern that has garnered significant attention both from the peerreviewed literature and popular media [1]. Bullying is prevalent throughout the United States [2] and globally impacting approximately $10-30 \%$ of children [3]. National Institutes of Health (NIH) report that $13 \%$ of children are involved in this behavior as a bully or perpetrator, $10.6 \%$ as a victim or target, and $6.3 \%$ as both bully and victim [2]. Participants in bullying (victims, bullies, and bully/victims) are at increased risk of many deleterious outcomes: low academic achievement [4], substance abuse [5], depression and suicide [6], problems with relationships [7], and several other indicators [1]. Addressing this problem, its predictors, propagating behaviors and outcomes is of great public health concern.

Significant bullying prevention strategies have been developed [8,9]. The Olweus Bullying Prevention Program is perhaps the most widespread and well-known program [10]. This program focuses on school environment and uses teachers as principle sources for implementation. Other programs involve adolescent students in the process of planning and implementing anti-bullying strategies [11]. Several school-programs have aimed at reducing bullying and victimization $[12,13]$; however, the most effective programs appear to be comprehensive approaches that include children, families, communities, and schools [9, 14]. More recent preventive approaches include media campaigns utilizing social media such as the 'It Gets Better' campaign and 'The Trevor Project,' which address bullying behavior and the LGBT community $[15,16]$.

Public Service Announcements (PSAs) or mass-media efforts have been an instrumental part of public health campaigns for many years $[17,18]$. PSAs have been used to promote a wide variety of health behaviors and healthrelated topics $[19,20]$. Web 2.0 technologies provide the opportunity to post PSAs on social networking and video sharing sites such as YouTube at no cost to a potentially limitless audience. With the growth of Web 2.0 capabilities much focus in public health research has shifted towards how to effectively use social networking sites for health promotion [21, 22]. 
Research has also begun examining how to most effectively use social media tools for health promotion [23]. Examining the inclusion of established health behavior change theoretical constructs in social media-based interventions and health promotion efforts is an area of emerging research. Doshi, and colleagues evaluated physical activity websites for inclusion of health behavior change theory constructs [24]. Similar content analyses of healthrelated mobile phone applications have been conducted [25, 26]. Recent content analyses of both obesity-related [27] and anti-smoking-related [28] videos posted to YouTube have similarly been completed. To date no study has explored the inclusion of health behavior change constructs in bullying-related PSAs posted on YouTube. The purpose of this paper is to examine health behavior theory content of anti-bullying YouTube PSAs, and other YouTube videos containing an anti-bullying message. Specifically, this paper looks at health behavior theory constructs used in antibullying videos and explores related factors with inclusion of theoretical constructs.

\section{Methods}

\subsection{Study design}

This study design comprised a content analysis for health behavior theory of anti-bullying YouTube videos. Videos were selected from www.YouTube.com using specific search terms typed into the YouTube search tool bar. Three graduate students trained in health behavior theory coded the videos.

\subsection{Sample}

The sample was derived from videos available on YouTube during the second week of October, 2012. Specific dates of searches for each of the five search terms were tracked accordingly. Anti-bullying videos/PSAs were identified through five specific search terms: "bullying campaign," "stop bullying," "bullying PSA," "anti-bullying," and "cyber bullying PSA." These terms were selected based on variation in video results obtained from searching an array of possible search terms. Preliminary search results returned 107,840 possible videos. Specific inclusion criteria were established in the initial development of the sample for purposes of narrowing results.

Videos longer than 4 minutes and 30 seconds were excluded after initial searches to eliminate short films, personal blogs, and films that did not fit a PSA format. Videos were also excluded for having less than 1,000 views in effort to only identify higher quality videos with increased viewership. Additionally, news stories were excluded due to a high unlikelihood of containing health behavior theory constructs.

YouTube.com groups search results onto pages of 25 each, with the most relevant (or most viewed) videos appearing first in ascending order. On average 2-3 videos per page are advertisements, narrowing the results to approximately 22 videos per page. To manage the significant number of video results, coders viewed all results per page until either reaching 60 videos to add to the sample or reaching a saturation point-meaning viewing multiple pages in a row and not finding any relevant videos for the sample.

All video links that met the inclusion criteria were copied and placed on a spreadsheet shared by the researchers. Following this first inclusion process and accounting for duplicates, the total sample included 274 videos. An additional 16 videos were excluded based on issues regarding relevance to anti-bullying messaging. Finally, a search was conducted online for anti-bullying campaigns and websites which were included in the sample in an effort to have a complete representative sample of available anti-bullying PSAs. These campaigns included The Trevor Project, stopbullying.gov, the It Gets Better Project, Think before You Speak, I Choose, and the Grin Campaign. Only videos from The Trevor Project, and the It Gets Better Project met the study inclusion criteria (N=6). The total sample of videos coded was 264 .

\subsection{Procedure}

Coders viewed study videos by selecting the appropriate link from the shared spreadsheet. First the coders viewed each video in its entirety recording key background on each video. Coders then evaluated each video according to the study instrument and entered scores directly into an electronic database.

\subsection{Measurement}

The study instrument included several key descriptive variables such as bullying setting, target audience, bullying behavior, gender, ethnicity, professionalism, and content validity (see Table 1). Theoretical constructs used to code the videos were adapted from the work of Doshi et al. (2003) who evaluated theoretical content of websites designed to 
promote physical activity. Doshi et al. (2003) used four prominent theories of behavior change: health belief model, the theory of reasoned action/planned behavior, the transtheoretical model, and the social cognitive theory/social learning theory. The current study instrument coded for each of these prominent theories as well as specific constructs designed to measure social capital [29]. As shown in Table 2, there were 22 total theoretical constructs coded for in the current study.

\subsection{Interrater reliability}

Three coders independently coded $10 \%(n=26)$ of the sample, $5 \%$ at the beginning and $5 \%$ at the end, in order to verify interrater reliability and check for rater drift. A Cohen's kappa coefficient was calculated both at the beginning and the end of sampling to measure interrater agreement $(\mathrm{k}=.5 \& \mathrm{k}=.5)$. The coefficients measured are categorized as moderate agreement in a division from .41 to .60 , and are acceptable levels of interrater agreement [30].

\subsection{Analysis}

Each YouTube video was coded for a total of 22 theoretical constructs. The constructs were subsequently scored using a dichotomous scale $(1=$ construct present, $0=$ construct not present), and totaled for each video to obtain a continuous total theory score (out of 22). Multiple regression analysis was used to determine the relationship between theory presence and total video views, length of video, publisher of the video, videos targeting bullies or victims, method of communicating PSA message, and containing links to other websites.

\section{Main results}

Characteristics of YouTube videos are presented in Table 1. The majority of videos (75\%) were created for addressing bullying in a school setting, as well as targeting generic bullying behavior (88\%). More than half of the sample (58\%) was created to specifically address the bully, with a similar percentage $(57 \%)$ created for a central audience of a victim (multiple responses were available for some questions which explains percentages not adding to 100). The most common bullying behaviors addressed in the videos were physical (42\%), verbal (54\%), and cyber-bullying (38\%). Only $3 \%(\mathrm{~N}=8)$ of the videos included citation for data referenced.

Table 1: Characteristics of study videos, $n=264$

\begin{tabular}{|c|c|c|}
\hline Characteristic & Variable & Percent $(\%)$ \\
\hline \multirow[t]{4}{*}{ Central Audience } & Bully & 58.33 \\
\hline & Victim & 57.57 \\
\hline & Bully/Victim & 3.41 \\
\hline & Non-Participant & 50.38 \\
\hline \multirow[t]{2}{*}{ Bullying Setting } & In-school & 74.62 \\
\hline & Out-of-school & 36.36 \\
\hline \multirow{5}{*}{ Targets of Bullying } & LGBT & 14.39 \\
\hline & Race/Minority & 4.92 \\
\hline & Obesity & 6.43 \\
\hline & Deviant Appear. & 12.88 \\
\hline & Generic Bullying & 87.87 \\
\hline \multirow[t]{5}{*}{ Bullying Behavior } & Physical & 41.67 \\
\hline & Verbal & 54.17 \\
\hline & Social Exclusion & 20.45 \\
\hline & Rumors & 14.77 \\
\hline & Cyber-Bullying & 37.88 \\
\hline \multirow[t]{7}{*}{ Professionalism } & Students (11-18 assignment) & 30.86 \\
\hline & Students (11-18 old Personal Video) & 21.59 \\
\hline & School Administration & 1.14 \\
\hline & Students (University) & 1.14 \\
\hline & Professional (Corporation) & 9.47 \\
\hline & Professional (NGO/Non-Profit) & 23.48 \\
\hline & Professional (Health Department) & 2.27 \\
\hline \multirow[t]{2}{*}{ Content Validity } & No Cite Research & 96.59 \\
\hline & One+ Reference & 3.41 \\
\hline \multirow[t]{6}{*}{ Methods of Comm. } & Scare Tactics & 10.6 \\
\hline & Emotional & 51.14 \\
\hline & Strictly Info. & 41.67 \\
\hline & Humor & 5.3 \\
\hline & Celebrity & 18.18 \\
\hline & Other & 8.71 \\
\hline
\end{tabular}


Table 2 shows the percentage of videos using specific theoretical constructs. Coded theories that were most commonly found in videos were general information (72\%), informational support (51\%), perceived risks (40\%), and self-efficacy (25\%). The mean theoretical score was 5.39 and the standard deviation was 3.1 .

YouTube videos were compared by their use of the five major health behavior theories (Table 3). The top five videos based on theory scores and the top five videos based on number of views are shown in the table. The theories with the highest overall percentage being used in the sample of YouTube videos were Theory of Planned Behavior (28.5\%), and Health Belief Model (28.4\%). Social Cognitive Theory was the least used theory in this sample (11.8\%).

Results from the multiple regression analysis (Table 4) revealed that containing links to other websites $(\mathrm{p}<.001)$ was positively associated with the inclusion of health behavior theory constructs. Theory was also positively associated with the number of views $(\mathrm{p}<.05)$. The interaction between targeting bullies and the inclusion of health behavior theory was significant $(p<.05)$ and negatively associated, while the interaction between targeting victims and the inclusion of health behavior theory was significant $(\mathrm{p}<.05)$ and positively associated.

\begin{tabular}{|c|c|c|c|}
\hline $\begin{array}{l}\text { Health Behavior Theory } \\
\text { Construct }\end{array}$ & Study Variable & Description & $\begin{array}{l}\text { \% of Videos } \\
\text { Containing } \\
\text { Construct }\end{array}$ \\
\hline Knowledge & General information & Provides general information about bullying & 72.35 \\
\hline \multirow[t]{6}{*}{ Cognitive } & Perceived Benefits & Pros about speaking up, interfering w/ bullying, not bullying & 9.47 \\
\hline & Perceived Barriers & Cons to speaking up or interfering w/ bullying & 1.52 \\
\hline & Perceived Risks & Info addressing risks to being vocal, standing up & 39.77 \\
\hline & Self-Efficacy & $\begin{array}{l}\text { Mentions concept or importance of confidence building in } \\
\text { relation to acting out against bully }\end{array}$ & 24.62 \\
\hline & Self-Talk & Examples of self-statements (encouragement) & 5.30 \\
\hline & Perceived Social Norms & $\begin{array}{l}\text { Addresses social norms in relation to bullies and victims, and } \\
\text { behavior }\end{array}$ & 6.06 \\
\hline \multirow[t]{5}{*}{ Behavioral } & Self-Monitoring & Techniques for monitoring behavior for victims & 0.0 \\
\hline & Stimulus-Control & $\begin{array}{l}\text { Cues and prompts for non-participants to interfere with } \\
\text { bullying }\end{array}$ & 0.0 \\
\hline & Self-Reward & Self-praise for interfering, or being a non-passive victim & 0.0 \\
\hline & Social Support & How to increase or utilize social support & 15.15 \\
\hline & Modeling/Vicarious Learn & $\begin{array}{l}\text { Viewer sees new behavior/method to address } \\
\text { bullying/victimization }\end{array}$ & 12.88 \\
\hline \multirow[t]{2}{*}{ Emotion Focused } & Stress Management & $\begin{array}{l}\text { Techniques to address behaviors that enable victimization to } \\
\text { occur (Bully/victims) }\end{array}$ & 0.0 \\
\hline & Negative Affect Manage. & $\begin{array}{l}\text { Guidelines to address mood managing for all participants } \\
\text { (bully, victim, bully/victim) }\end{array}$ & 3.03 \\
\hline \multirow[t]{4}{*}{ Therapeutic Interventions } & Skill-Building & Guidelines on new behaviors to address bullying & 9.09 \\
\hline & Increasing Knowledge & Provides resources to get additional info & 18.94 \\
\hline & Assess Motivational Readiness & Addresses stage of change viewer is in & 0.0 \\
\hline & Ongoing Feedback & Provides method of obtaining follow-up or additional help & 0.0 \\
\hline \multirow[t]{4}{*}{ Social Capital } & Emotional Support & Empathy, love, trust, caring & 13.64 \\
\hline & Instrumental Support & Tangible aid, services (e.g. Phone number/ chat) & 6.82 \\
\hline & Informational Support & Advice, suggestions, info (website/ parent) & 50.76 \\
\hline & Appraisal Support & $\begin{array}{l}\text { Information that is useful for self-evaluation, constructive } \\
\text { feedback, affirmation }\end{array}$ & 1.52 \\
\hline
\end{tabular}

Table 3: Health behavior theories and view counts in top performing videos

\begin{tabular}{|c|c|c|c|c|c|c|}
\hline Video Name & $\begin{array}{l}\text { Health } \\
\text { Belief Model } \\
\%\end{array}$ & $\begin{array}{l}\text { Trans- } \\
\text { theoretical } \\
\text { Model \% }\end{array}$ & $\begin{array}{l}\text { Theory of } \\
\text { Planned } \\
\text { Behavior \% }\end{array}$ & $\begin{array}{l}\text { Social } \\
\text { Cognitive } \\
\text { Theory \% }\end{array}$ & $\begin{array}{l}\text { Social Capital } \\
\%\end{array}$ & $\begin{array}{l}\text { Total Theory } \\
\text { Score } / 22\end{array}$ \\
\hline \multicolumn{7}{|l|}{ Top 5 Videos: Theory Scores } \\
\hline Stop Non-Stop Bullies & 40 & 38.5 & 50 & 38.5 & 60 & 18 \\
\hline $\mathrm{ABC}-$ Anti Bullying Crew & 40 & 30.8 & 33.3 & 30.8 & 80 & 15 \\
\hline Stop Bullying: Speak Up - Level Up & 60 & 53.8 & 83.3 & 46.2 & 40 & 15 \\
\hline Glee's Max Adler: It Gets Better & 0.0 & 15.4 & 33.3 & 15.4 & 60 & 14 \\
\hline Stop Bullying: Speak Up - Junior Dudes & 40 & 38.5 & 50 & 38.5 & 40 & 14 \\
\hline \multicolumn{7}{|l|}{ Top 5 Videos: Views } \\
\hline Anti-Bullying ad & 40 & 15.4 & 33.3 & 15.4 & 20 & 6 \\
\hline Chris Colfer for the Trevor Project & 40 & 23.1 & 50 & 30.8 & 60 & 14 \\
\hline Words Hurt - Bullying Commercial & 20 & 7.7 & 16.7 & 7.7 & 20 & 4 \\
\hline $\begin{array}{l}\text { Stand Up! - Don't Stand for Homophobic } \\
\text { Bullying }\end{array}$ & 60 & 30.8 & 83.3 & 15.4 & 40 & 11 \\
\hline Anti-Bullying Awareness & 40 & 7.7 & 33.3 & 7.7 & 20 & 4 \\
\hline Total Average Mean \%: & 28.4 & 12.5 & 28.5 & 11.8 & 17.6 & ---- \\
\hline
\end{tabular}


Table 4: Regression analyses for inclusion of health behavior theory, $\mathrm{n}=264$.

\begin{tabular}{|c|c|c|c|c|c|}
\hline Variable & Coefficient & Standard Error & tValue & pValue & $\begin{array}{l}\text { 95\% Confidence } \\
\text { Interval }\end{array}$ \\
\hline Number of Views & .0003 & .0001 & 2.06 & 0.040 & {$[.0000, .0007]$} \\
\hline Time in Seconds & .0005 & .0005 & 0.98 & .328 & {$[-.0005, .0016]$} \\
\hline Video Publisher & -.0209 & .0875 & -0.24 & 0.811 & {$[-.1932, .1514]$} \\
\hline Targeting Bullies & -.1922 & .0782 & -2.46 & 0.015 & {$[-.3461,-.0382]$} \\
\hline Targeting Victims & .1733 & .0787 & 2.20 & 0.029 & {$[.0182, .3284]$} \\
\hline Strictly Informational Messaging & .4706 & .0782 & 6.02 & 0.000 & {$[.3166, .6246]$} \\
\hline Contains Links to Other Websites & .5333 & .0934 & 5.71 & 0.000 & {$[.3494, .7172]$} \\
\hline
\end{tabular}

Note. Number of Observations $=264 . R^{2}=0.27$

\section{Discussion}

This content analysis evaluated the theoretical content of 264 anti-bullying videos found on YouTube. Results demonstrate that most videos did not incorporate established health behavior theoretical constructs. Most videos addressed generic bullying taking place within schools, which makes sense as this setting is relevant for the adolescent target demographic. Of the behaviors represented, most videos addressed direct forms of bullying; with verbal bullying being the most prevalent, followed by physical bullying. Indirect forms of bullying received less attention: social exclusion was represented half as often as physical bullying, and other relational bullying, such as rumor spreading, was the least represented. This is significant, as males are more likely to be involved in bullying and to be victimized by direct forms of bullying, while females report similar levels of victimization, but in its indirect forms [31, 32]. Videos addressed cyber-bullying less frequently than direct bullying, but more frequently than indirect bullying. This is an important area to address, as cyber-bullying often co-occurs with other bullying behaviors in both males and females [33].

Overall, theoretical content was lacking in the majority of videos. Of the theoretical models coded for, the Theory of Planned Behavior was the most prevalent, followed by the Health Belief Model. This may in part be due to the significant overlap between theories [34]. For instance, both models involve increasing knowledge as a means of influencing beliefs, attitudes, or behavior [24]. Of the theoretical constructs coded for, the most prevalent were general information-facts and statistics related to bullying - and informational support, typically in the form of links to websites inviting viewers to learn more. Theory-based behavioral strategies had a much lower representation in this sample. This is consistent with findings from content analyses of other technological mediums like websites [24] and physical activity apps [25]. This may indicate the limitations of YouTube videos as a medium of using theory to initiate change in audience behavior.

Despite more than half of the videos addressing viewers' informational needs, the majority did not cite resources, so content validity could not be established. However, a related content analysis of YouTube videos related to HPV vaccination has indicated a high volume of misinformation pertaining to the vaccine [35]. Future research is needed to evaluate the accuracy and quality of information and recommendations presented in videos aimed at bullying prevention.

Self-efficacy was represented in only one-fourth of the videos evaluated, despite the potential importance of this construct in taking action against bullying in any role addressed. Self-efficacy has been shown to be an important skill in mediating the effects of bullying on its victims, serving a protective function against anxiety, depression, and, possibly, retaliatory aggression toward others [36]. Among bystanders, research has indicated a positive association between level of self-efficacy and the likelihood of intervening in bulling situations [37, 38]. Videos emphasizing selfefficacy among victims could potentially be instrumental in averting some of the negative individual and social outcomes associated with bullying.

As the third most represented theory, Social Capital was included in less than one-fifth of the videos. Considering the interpersonal nature of the problem, especially with respect to its perpetuation and its solutions, this finding is surprising. Higher levels of social capital are positively associated with greater resilience, mitigating negative outcomes in unfavorable environments [39]. Specific to bullying, multiple studies have demonstrated that having friends is a protective factor against victimization [40-43]. Conversely, social groups and structures within schools may serve to reinforce and perpetuate bullying behavior [44]. Students' relationships with their peers, as well as their perceptions of peer expectations have a greater influence on bullying-related behavior than does their perception of authority figures' expectations [45]. Due to the powerful role of social factors, video creators would be wise to address social capital in their productions. 
Higher theory scores were positively associated with higher view counts. This could indicate that theory-based videos attract a larger viewership than those without theory. However, this finding should be interpreted conservatively due to the number of views not necessarily being representative of popularity - as it does not take the age of the video into account. Thus, some more recently uploaded videos may garner many views early on; while older videos may have accumulated very few views relative to their "lifespan." Adjusting for this, or looking at other variables, such as viewer comments, may give a more comprehensive representation of audience engagement and impact.

Interestingly, there was no correlation between the professionalism of videos and their theoretical content scores. In other words, regardless of its source a video produced by a health department or other professional organization was no more likely to incorporate theory than one made by an individual or individuals, including adolescents. This is consistent with a recent study which found no significant association between video source and content based on the factors of the Health Belief Model [35]. Other research has found no difference in the influence on viewer attitudes and behavioral intention in young people watching pro-social YouTube videos created by peers versus issue-experts [46]. Whether this lack of influence should be attributed to the inherent challenge in influencing these factors via advertising, as was postulated by Paek et al., or due to the similarly low levels of theoretically-based behavior-change content between both sources, is a question that will require future research.

\subsection{Limitations}

Several key limitations may impact the interpretation of results from this study. First, the search terms for this study were limited as YouTube is a rather large database of videos, and certain media campaigns and videos may have been left out of the sample unintentionally. To control for this, a search was conducted of major bullying campaigns through the Google search engine yielding additional videos that were added to the sample according to inclusion criteria. Furthermore, the theoretical constructs that were coded for, as adapted from Doshi et al, were not all relevant to bullying behavior. For this reason certain constructs were dropped from the original set and constructs from Social Capital were added — which are much more relevant to bullying behavior.

Finally, the sample is not a complete representation of bullying videos on YouTube. Since this database in extremely comprehensive and expansive, it would be almost impossible to actually search and code all relevant videos. Additionally, YouTube is not the only source of social media videos on the internet. However, searches were conducted for large PSA campaigns and search results are structured so that the most relevant videos are placed at the beginning of the results. These factors put together should greatly minimize any misrepresentation bias that could have occurred in the initial development of the sample.

\section{Conclusion}

Despite these limitations, this paper represents the first in-depth content analysis of health behavior theoretical constructs in YouTube videos targeting bullying PSAs. Similar research has been conducted to date on content of YouTube videos [27, 28], and using social media effectively [21]. This paper has implications for public health practice in utilizing social media; in particular, the effective use of YouTube. Organizations and others desiring to promote health via videos on YouTube should include health behavior theories when developing their videos in order to make them more effective facilitators of change, and to achieve higher numbers of views. Overall anti-bullying videos on YouTube are ineffective in both utilizing theory and in attracting viewership. Research has indicated that, while people select and view YouTube videos both for entertainment and to gain information, they are more likely to share entertaining videos with others [47]. Those wanting to reach a large audience should keep this in mind when creating PSAs. Future research and public health practice should focus on effectively utilizing YouTube as a means to disperse public health messages to greater numbers of people.

\section{References}

[1] C.R. Cook, et al., Predictors of bullying and victimization in childhood and adolescence: A meta-analytic investigation, School Psychology Quarterly 25:2 (2010) 65-83.

[2] T.R. Nansel, et al., Bullying behaviors among US youth, JAMA: Journal of the American Medical Association $285: 16$ (2001) 2094.

[3] M.E. Solberg, D. Olweus, Prevalence estimation of school bullying with the Olweus Bully/Victim Questionnaire, Aggressive Behavior 29:3 (2003) 239-268.

[4] A.G. Carney, K.W. Merrell, Bullying in schools: Perspectives on understanding and preventing an international problem, School Psychology International 22:3 (2001) 364-382. 
[5] B. Houbre, et al., Bullying among students and its consequences on health, European Journal of Psychology of Education 21:2 (2006) 183208.

[6] K. Kumpulainen, et al., Bullying and psychiatric symptoms among elementary school-age children, Child Abuse \& Neglect 22:7 (1998) 705717.

[7] W.M. Craig, D.J. Pepler, Identifying and targeting risk for involvement in bullying and victimization, Canadian Journal of Psychiatry 48:9 (2003) 577.

[8] P.R. Smokowski, K.H. Kopasz, Bullying in school: An overview of types, effects, family characteristics, and intervention strategies, Children \& Schools 27:2 (2005) 101-110

[9] J.A.J. Barbero, B.L.E. Hernandez, G. M.P, Effectiveness of anti-bullying school programmes: A systematic review by evidence levels, Children and Youth Services Review 34 (2012) 1646-1658.

[10] D. Olweus, S.P. Limber, Bullying in school: Evaluation and dissemination of the Olweus Bullying Prevention Program, American Journal of Orthopsychiatry 80:1 (2010) 124-134.

[11] A. Frisen, K. Holmqvist, Adolescents' own suggestions for bullying interventions at age 13 and 16, Scandinavian Journal of Psychology 51:2 (2010) 123-131.

[12] J. Jenson, W. Dieterich, Effects of a skills-based prevention program on bullying and bully victimization among elementary school children, Prevention Science 8:4 (2007) 285-296.

[13] K.S. Frey, et al., Reducing playground bullying and supporting beliefs: An experimental trial of the steps to respect program, Developmental Psychology 41:3 (2005) 479-490.

[14] J.D. Hawkins, et al., Preventing adolescent health-risk behaviors by strengthening protection during childhood, Archives of Pediatric Adolescent Medicine 153 (1999) 226-234

[15] A. Muller, Virtual communities and translation into physical reality in the 'It Gets Better' project. Journal of Media Practice 12:3 (2011) 269277.

[16] Entertainment Close - Up. Lady Gaga, The Trevor Project and the It Gets Better Project Join Mediaplanet in 'Speak Out' Campaign. Revised 2011. Accessed November 2012.

[17] D.E. Apollonio, and R.E. Malone, Turning negative into positive: public health mass media campaigns and negative advertising, Health Education Research 24:3 (2009) 483-495.

[18] W. Randolph, K. Viswanath, Lessons learned from public health mass media campaigns: Marketing health in a crowded media world, Annual Review of Public Health 25:1 (2004) 419-437.

[19] J.E. Leavy, et al., Physical activity mass media campaigns and their evaluation: A systematic review of the literature 2003-2010, Health Education Research 26:6 (2011) 1060-1085.

[20] C. Pechmann, E.T. Reibling, Anti-smoking advertising campaigns targeting youth: Case studies from USA and Canada, Tobacco Control 9:2 (2000) 18-31.

[21] B. Freeman, S. Chapman, Gone viral? Heard the buzz? A guide for public health practitioners and researchers on how Web 2.0 can subvert advertising restrictions and spread health information, Journal of Epidemiology \& Community Health 62:9 (2008) 778-782.

[22] J.M. Kapp, et al., Updating public health teaching methods in the era of social media, Public Health Reports 124:6 (2009) 775-777.

[23] R.D. Waters, P.M. Jones, Using video to build an organization's identity and brand: A content analysis of nonprofit organizations' YouTube videos, Journal of Nonprofit \& Public Sector Marketing 23:3 (2011) 248-268.

[24] A. Doshi, et al., Evaluation of physical activity web sites for use of behavior change theories, Annals of Behavioral Medicine 25:2 (2003) 105.

[25] L.T. Cowan, et al., Apps of steel: Are exercise apps providing consumers with realistic expectations? A content analysis of exercise apps for presence of behavior change theory, Health Education \& Behavior (2012).

[26] J.H. West, et al., There's an app for that: Content analysis of paid health and fitness apps, Journal of Medical Internet Research 14:3 (2012)

[27] J.H. Yoo, J. Kim, Obesity in the new media: A content analysis of obesity videos on YouTube, Health Communication 27:1 (2012) 86-97.

[28] H.J. Paek, K. Kim, T. Hove, Content analysis of antismoking videos on YouTube: Message sensation value, message appeals, and their relationships with viewer responses, Health Education Research 25:6 (2010) 1085-1099.

[29] K. Glanz, B.K. Rimer, K. Viswanath, Health Behavior and Health Education: Theory, Research, and Practice. 4 ed, Jossey-Bass, San Francisco, CA, 2008.

[30] R. Landis, G. Koch, The measurement of observer agreement for categorical data. Biometrics 33 (1977) 159-174

[31] M.J. Boulton, M. Trueman, I. Flemington, Associations between secondary school pupils' definitions of bullying, attitudes towards bullying, and tendencies to engage in bullying: Age and sex differences, Educational Studies 28:4 (2002) 353-370.

[32] A. Frisén, K. Holmqvist, D. Oscarsson, 13-year-olds' perception of bullying: definitions, reasons for victimization and experience of adults' response, Educational Studies 34:2 (2008) 105-117.

[33] J. Wang, R.J. Ianotti, J.W. Luk, Bullying victimization among underweight and overweight U.S. youth: Differential associations for boys and girls, Journal of Adolescent Health 47:1 (2010) 99-101.

[34] M. Gerend, J. Shepherd, Predicting human papillomavirus vaccine uptake in young adult women: Comparing the health belief model and theory of planned behavior, Annals of Behavioral Medicine 44:2 (2012) 171-180.

[35] R. Briones, et al., When vaccines go viral: An analysis of HPV vaccine coverage on YouTube, Health Communication 27:5 (2012) 478-485.

[36] P. Singh, K. Bussey, Peer victimization and psychological maladjustment: The mediating role of coping self-efficacy, Journal of Research on Adolescence 21:2 (2011) 420-433.

[37] V. Pöyhönen, J. Juvonen, C. Salmivalli, Standing up for the victim, siding with the bully or standing by? Bystander responses in bullying situations, Social Development 21:4 (2012) 722-741.

[38] G. Gini, et al., Determinants of adolescents' active defending and passive bystanding behavior in bullying, Journal of Adolescence 31:1 (2008) 93-105.

[39] K.M. Fitzpatrick, et al., Depressive symptomatology, exposure to violence, and the role of social capital among African American adolescents, American Journal of Orthopsychiatry 75:2 (2005) 262-274.

[40] A.D. Pelligrini, M. Bartini, School bullies, victims, and aggressive victims: Factors relating to group affiliation, Journal of Educational Psychology 91:2 (1999) 216.

[41] A.D. Pellegrini, M. Bartini, A longitudinal study of bullying, victimization, and peer affiliation during the transition from primary school to middle school, American Educational Research Journal 37:3 (2000) 699-725.

[42] E.V.E. Hodges, D.G. Perry, Personal and interpersonal antecedents and consequences of victimization by peers, Journal of Personality and Social Psychology 76:4 (1999) 677-685.

[43] M.K. Demaray, C.K. Malecki, Perceptions of the frequency and importance of social support by students classified as victims, bullies, and bully/victims in an urban middle school, School Psychology Review 32:3 (2003) 471-489. 
[44] C. Salmivalli, A. Huttunen, K.M.J. Lagerspetz, Peer networks and bullying in schools, Scandinavian Journal of Psychology 38:4 (1997) 305312 .

[45] K. Rigby, Why do some children bully at school? The contributions of negative attitudes towards victims and the perceived expectations of friends, parents and teachers, School Psychology International 26:2 (2005) 147-161.

[46] H.-J. Paek, et al., Peer or expert? The persuasive impact of YouTube public service announcement producers, International Journal of Advertising 30:1 (2011) 161.

[47] P. Haridakis, G. Hanson, Social interaction and co-viewing with YouTube: Blending mass communication reception and social connection, Journal of Broadcasting \& Electronic Media 53:2 (2009) 317-335. 